\title{
WORKING
}

paper

\section{Public Opinion on Central Banks when Economic Policy is Uncertain ${ }^{1}$}

\author{
Klodiana Istrefi ${ }^{2}$ and Anamaria Piloiu ${ }^{3,4}$
}

\author{
April 2020, WP \#765
}

\begin{abstract}
This paper investigates whether uncertainty about economic policy plays a role in shaping the credibility and reputation of the central bank in the eyes of the public. In particular, we look at the effect of policy uncertainty for the dynamics of citizens' opinion, being trust, satisfaction or confidence, in the European Central Bank, the Bank of England and the Bank of Japan. Estimating Bayesian VARs for the period 1999-2014, we find that shocks to economic policy uncertainty induce economic contractions and relatively sharp deterioration in trust or satisfaction measures, which in general take longer than economic growth to rebuild.
\end{abstract}

Keywords: Policy Uncertainty; Central Banks; Public Opinion; Structural VAR.

JEL classification: E02, E31, E58, E63, P16

${ }^{1}$ We thank Sandra Eickmeier, Stefan Gerlach, Charles Kahn, Philipp Harms, Jean-Guillaume Sahuc, Isabel Schnabel, Balazs Vonnak, Mirko Wiederholt, Volker Wieland and the participants in the 3rd Ifo Conference on Macroeconomics and Survey Data, the17th Conference on Macroeconomic Analysis and International Finance, the Lisbon Meeting on Institutions and Political Economy and the GSEFM Summer Institute for helpful discussions and comments.

${ }^{2}$ Banque de France, klodiana.isterfi@banque-france.fr

${ }^{3}$ European Central Bank, anamaria.piloiu@ecb.europa.eu 


\section{NON-TECHNICAL SUMMARY}

In this paper, we ask whether uncertainty about economic policies plays a role in shaping the credibility and reputation of the central bank in the eyes of the public. To this aim, we study the role of policy uncertainty on survey-based measures of public opinion (trust, satisfaction and confidence) on central banks. Public trust and confidence in central banks are important for the effectiveness of the monetary policy. Trust and credibility are particularly important to have well-anchored inflation expectations, both in good and bad times.

The central banks under our investigation are the European Central Bank (ECB), the Bank of England (BoE) and the Bank of Japan (BoJ). The choice is constrained by the availability of measures of public opinion on central banks. We obtain these measures from the Eurobarometer survey (ECB), the Inflation Attitudes survey (BoE) and the Public Opinion survey $(\mathrm{BoJ})$, respectively. The two latter surveys are published by the respective central banks. These surveys seek to gauge the confidence of citizens on the monetary institution and/or their satisfaction with the way the central bank is doing its job to preserve price stability. To measure policy uncertainty we rely on the news-based Economic Policy Uncertainty (EPU) index of Baker, Bloom and Davis (2016). The EPU captures uncertainty about what policy actions the decision makers will undertake and uncertainty about the economic effects of current and future actions and/or inactions. This can be uncertainty about fiscal, monetary or other regulatory policies.

The hypothesis is that high uncertainty about policies might reduce trust and confidence on the institutions responsible for economic policy. This effect could be both direct and indirect through the effect that uncertainty has on the economy, notably on growth, unemployment and prices. Moreover, positive or negative attitudes on institutions could also affect the response of the economy to high uncertainty, by accelerating or dragging the recovery. We study these dynamic relationships through a Bayesian VAR framework. We link economic policy uncertainty with measures of public opinion on central banks while accounting for variables that seem important for building confidence on such institutions, like the industrial production, inflation and the unemployment rate. We use data for Germany, France, Italy, Spain, and United Kingdom for the period 1999 - 2014 and 2003 - 2014 for Japan.

Overall, we find that shocks to uncertainty induce economic contractions and a relatively sharp deterioration in trust or confidence measures, which generally take longer than economic activity to reverse back to initial levels (see Figure 1). This reinforces the idea that confidence is easy to lose but hard to gain. We observe the strongest drop in trust for Italy, followed by Spain and France. Thus, uncertainty has a negative effect on macroeconomic outcomes (in line with previous studies) but also shapes the dynamics of public opinion on central banks in Europe (the BoE and the ECB). The case of $\mathrm{BoJ}$ is not clear from the data.

The deterioration of public confidence in response to heightened policy uncertainty should be worrying for policymakers. In the current environment of low interest rates, trust and credibility in the central bank is even more important for the success of policies that rely on commitment on future actions, like the forward guidance on rates and balance sheet policies.

The uncertainty studied in this paper relates to fiscal, monetary or regulatory policies. Thus, central banks seem to be held accountable even for issues that fall beyond their mandates. In response, a clear central bank communication not only to the specialised audiences but also to a wider public would enhance public understanding and support for central banks. 
Figure 1. Policy uncertainty and its effect on the measure of trust on the ECB.

(a) Germany
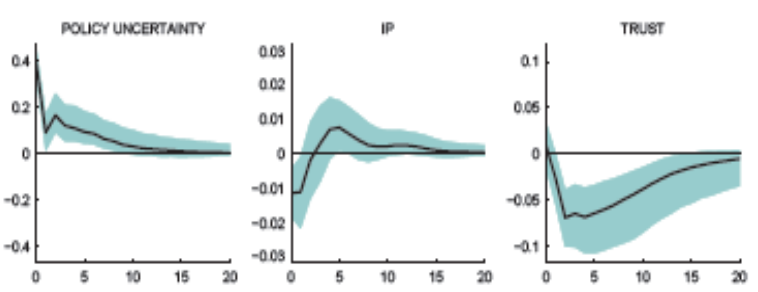

(c) Italy
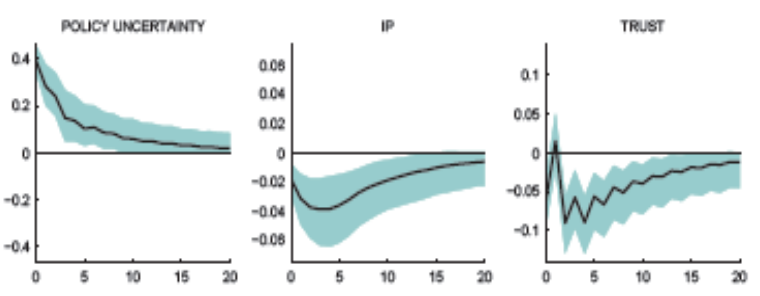

(b) France
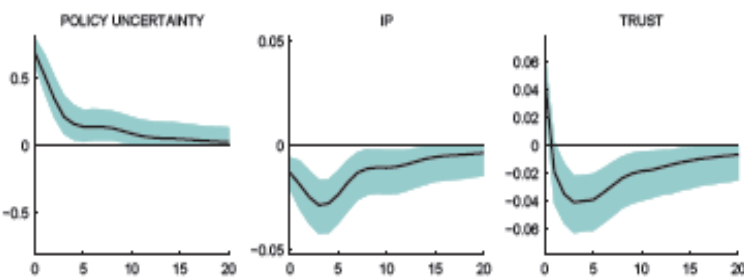

(d) Spain
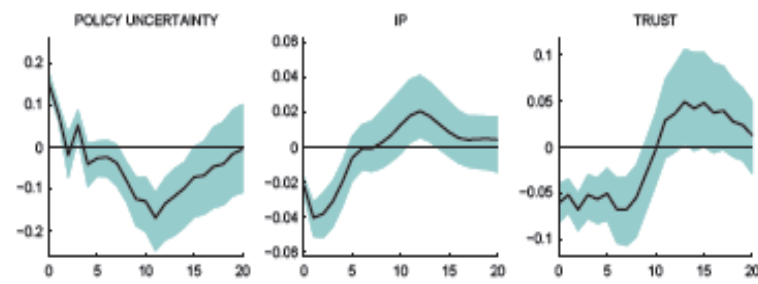

Notes: The figure shows the dynamic response of the Industrial Production (IP) and the measure of public opinion on the ECB (Trust) in response to a Policy Uncertainty shock, in selected euro area countries. A policy uncertainty shock is accompanied by immediate economic contractions (fall in the IP) and a slow but long lasting deterioration of the Trust measure. The solid line in black denotes median impulse response from an estimated Bayesian VAR (3). The shaded areas represent the corresponding 68 percent error band. The horizon period in the horizontal is in half years. VARs are estimated for the period 1999-2014.

\section{L'opinion publique sur les banques centrales lorsque la politique économique est incertaine}

\section{RÉSUMÉ}

Cet article examine dans quelle mesure l'incertitude en ce qui concerne la politique économique joue un rôle prépondérant quant à la crédibilité et la réputation de la banque centrale aux yeux du grand public. En particulier, nous mesurons les effets de l'incertitude politique sur l'opinion des citoyens, qu'il s'agisse de confiance ou de satisfaction, vis-à-vis de la Banque centrale européenne, la Banque centrale d'Angleterre et la Banque centrale du Japon sur la période 1999-2014. Nous constatons que les chocs liés à l'incertitude des politiques économiques entrainent inexorablement des contractions économiques et une détérioration relativement prononcée de nos mesures de confiance ou de satisfaction. Après un tel choc, ces dernières prennent généralement plus de temps à se reconstruire que la croissance économique.

Mots-clés : incertitude politique ; banques centrales ; croyances du public ; structure VAR 


\section{Introduction}

Central bank credibility and reputation are important for the effectiveness of monetary policy. Both can built up over time as the central bank performance improves or can diminish for a variety of reasons, such as a financial crisis, a serious crisis of confidence in the governor, or a political conflict between the monetary authority and the government (Bordo and Siklos, 2014). Central bank credibility has become even more important in the recent years, when many central banks, constrained by the effective lower bound on interest rates, resorted to unconventional policies like forward guidance and balance sheet policies. For instance, for forward guidance on rates to be successful, the public must trust that the central bank will not renege on her commitment to keep rates low for longer if economic conditions normalize.

Is there a role for policy uncertainty on central bank credibility? Theoretical contributions like in Howitt (1982) and Backus and Driffill (1985) suggest that scepticism, reputation and policy uncertainty play a role for inflation and especially for anti-inflation policies. For instance, when the general public is uncertain about the preferences of the policymaker, and therefore skeptical about its anti-inflation announcement, the disinflation process will be more costly in terms of higher output loss and unemployment. Nevertheless, empirical evidence on the dynamics between policy uncertainty, central bank's reputation or credibility is scarce. Using surveys of professional forecasters, Istrefi and Piloiu (2014) show that uncertainty about monetary policy can be harmful for the anchoring of long-term inflation expectations, which is generally believed to reflect the credibility of the central bank. However, professional forecasters represent only a small share of the agents in the economy. The way the general public judges or perceives the policy efforts of the central banks is also important. Their success in meeting their objectives depends, as well, on the support and understanding of the policy framework and policy decisions by the regular citizens. Furthermore, they are not only the largest share of agents in the economy but they also are generally less financially literate and more likely to get their information from and be influenced by the media.

In this paper we ask whether policy uncertainty plays a role in shaping the credibility and reputation of the central bank in the eyes of the general public. In the absence of measures of long-term inflation expectations of the general public, we study the role of policy uncertainty on survey-based measures of public opinion (trust, satisfaction and confidence) on central banks. Public trust and confidence in central banks are important in order to have well-anchored inflation expectations, both in good and bad times. To our knowledge, measures of public opinion are available only for the European Central Bank (ECB), the Bank of England (BoE) and 
the Bank of Japan (BoJ). We obtain data on these measures from the Eurobarometer survey (ECB), the Inflation Attitudes survey (BoE) and the Public Opinion survey (BoJ), respectively. The two latter surveys are published by the respective central banks. These surveys seek to gauge the confidence of citizens on the monetary institution and/or their satisfaction with the way the central bank is doing its job to preserve price stability.

We estimate structural Bayesian VARs, linking economic policy uncertainty with measures of public opinion on central banks while accounting for economic activity with variables that are considered to be important for building confidence on such institutions. We use the news-based Economic Policy Uncertainty (EPU) index of Bloom et al. (2016) as our measure of policy uncertainty. In our specification, economic activity is accounted for by different indicators: the industrial production index, the CPI inflation rate and the unemployment rate. The variables are aligned in the VAR specifications such that policy uncertainty is observed before the surveys of public opinion on central banks are collected. In this way we ensure that the EPU measure does not contemporaneously reflect the realizations of public opinion, allowing us to use a recursive identification strategy that orders policy uncertainty in front of public opinion measures in the VAR specifications.

The structural VARs are estimated on data for Germany, France, Italy, Spain, United Kingdom for the period 1999 - 2014 and for Japan for the period 2003 - 2014. Our main finding is that shocks to uncertainty induce economic contractions and a relatively sharp deterioration in confidence measures, which generally take longer than economic activity to reverse back to initial levels. This reinforces the idea that confidence is easy to lose but hard to gain or, as Bordo and Siklos (2014) state, credibility and reputation can be earned slowly and painstakingly but are susceptible to evaporate on a moment's notice. The strongest drop in public confidence in central banks in response to a policy uncertainty shock is observed for Italy, followed by Spain and then by France. The case of Japan is not as clear as the baseline result shows that this type of shock does not seem to affect the net confidence in BoJ, a results that is not supported in a robustness analysis. ${ }^{1}$

Our work relates to different strands of the literature. First we relate to empirical literature on the macroeconomic effects of policy uncertainty (Fernandez-Villaverde et al. (2015), Alexopoulos and Cohen (2009), Bloom et al. (2016), Leduc and Liu (2016), Mumtaz and Zanetti (2013) and Istrefi and Mouabbi (2018) among others). The general finding in this literature is that shocks to policy uncertainty are recessionary. The effect on unemployment is also found to be negative. For example,

\footnotetext{
${ }^{1}$ The data sample for Japan is too short to draw strong conclusions.
} 
Leduc and Liu (2016) show theoretically and empirically (on US and UK data) that uncertainty shocks are demand type of shocks, with inflation and output falling when uncertainty increases. Our results support the findings on the effect of policy uncertainty shocks on output and unemployment, for a number of countries. In addition, we show that the effect on prices is not as strongly pinned down. The sign effect is not robust to different specifications and across countries. More importantly, we add to this literature by showing that policy uncertainty has a negative effect on measures of public confidence in central banks.

Our work also relates with the empirical literature that studies the importance of trust and confidence for economic performance and for better functioning institutions. For example, Knack and Keefer (1997) show that cross-country measures of trust are positively related to the GDP growth and investment and Guiso et al. (2006) show that differences in cultural attitudes translate into differences in entrepreneurship and savings. Furthermore, related with institutions, Ehrmann and Fratzscher (2011) show that lack of trust weakens the central bank (the ECB) and makes it vulnerable to political pressure. Our framework allows measures of public confidence in central banks to feed back into the measures of uncertainty about the policy and also in the economy. In addition, we provide evidence for several central banks, allowing for interesting comparisons. ${ }^{2}$ While all central banks under our investigation have price stability as the primary objective, their monetary policy frameworks are different. The underlying economic conditions have also been quite different in the studied period across these countries. To our knowledge, in this context, we are also the first to employ and analyze public opinion measures from two novel datasets, the Inflation Attitudes Surveys for the BoE and the Public Opinion surveys for the BoJ.

The structure of the paper is as follows. Section 2 presents the measures of public opinion on central banks and an overview of their recent developments. Section 3 presents the empirical methodology (structural VAR estimations) and Section 4 the discussion of results. Section 5 concludes.

\section{Public opinion on central banks}

In the following we introduce measures of public opinion on central banks and their evolution in the recent years. For euro area countries we obtain data on trust in the ECB from the Eurobarometer surveys. In the case of the United Kingdom, we

\footnotetext{
${ }^{2}$ Several studies have attempted to quantify the determinants of trust in ECB, as Roth, Gros, and Nowak-Lehmann (2012a), Roth, Jonung, and Nowak-Lehmann (2012b) and Wälti (2012), Ehrmann et al. (2013) and Bursian and Furth (2015), among others.
} 
obtain information about the satisfaction of British citizens with the way the Bank of England is doing its job to preserve price stability from the Inflation Attitudes Survey published by the Bank of England. Information on the satisfaction of Japanese citizens with respect to the Bank of Japan is obtained from the Opinion Survey on the General Public's Views and Behavior published by the Bank of Japan.

$E C B$. The Eurobarometer survey of the European Commission provides information on a wide range of topics including perceptions about political institutions, both national governments and parliaments, and the European Union (EU) and its institutions. The standard Eurobarometer was established in 1973 and each survey consists of approximately 1000 face-to-face interviews per country. The survey is published on a biannual basis, spring and fall of each year. The field work for the spring wave is generally in May-June while the field work for the fall wave is in October-November. One of the topics covered in the survey is "Trust in European institutions" and under this category one of the questions asked is: "And, for each of them, please tell me if you tend to trust it or tend not to trust it? The European Central Bank". The possible answers from which the respondents can choose are: "Tend to trust", "Tend not to trust" and "DK - Don't know". Using this question, we build a measure of net trust in the ECB as the share of respondents in a country during a given survey which answer they trust the ECB, minus the share of respondents who do not trust. Our sample covers the period 1999 to 2014, comprising Eurobarometer EB51 to Eurobarometer EB82.

Bank of England. Since 1999 the BoE is publishing the Inflation Attitudes Survey, which is a survey of households' attitudes to inflation expectations and monetary policy. With this survey, the BoE seeks to quantify the impact of its efforts to increase the public's understanding of, and support for, its monetary policy framework. The survey is carried out on a quarterly basis, on adults aged 16 years and over using a random location sample designed to be representative of all adults in the UK. The questions asked seek information on public knowledge, understanding and attitudes toward the Monetary Policy Committee (MPC) process, as well as expectations of interest rates and inflation. They also look to measure satisfaction/dissatisfaction with the way the Bank of England is "doing its job". For our analysis we only focus on question 14 in the survey, which reads: "Overall, how satisfied or dissatisfied are you with the way the Bank of England is doing its job to set interest rates in order to control inflation?". The possible answers are: "Very satisfied", "Fairly satisfied", "Neither satisfied nor dissatisfied", "Fairly dissatisfied", "Very dissatisfied" and "No idea". We quantify the measure of net confidence as the difference between the total share of respondents who answer they are satisfied 
(very or fairly satisfied) and the total share of respondents who are not satisfied (very or fairly dissatisfied). The data sample used in our study covers the period 1999 to 2014.

Bank of Japan. The BoJ conducts the Opinion Survey on the General Public's Views and Behavior since 1993. The aim is to grasp how the public's current impression of household circumstances and changes in financial and economic conditions affect their perceptions and actions. This survey is conducted at a quarterly frequency with a nationwide sample of 4000 individuals who are at least 20 years of age. The question of our interest is asked only at a biannual frequency and it reads: "How would you describe your level of confidence in the Bank?". The possible responses are: "Confident", "Somewhat confident", "Difficult to say", "Not particularly confident" and "Not confident". As in the previous cases, we build the measure of confidence in the BoJ as the difference between the share of respondents who are confident (the sum of "Confident" and "Somewhat confident") and the share of respondents who are not confident (the sum of "Not particularly confident" and "Not confident") in the BoJ. These data are available at the BoJ website, starting in 2003. Our sample ends in 2014.

\subsection{Recent developments in public opinion on central banks}

In the light of extraordinary events following the financial crisis of 2007-08, monetary authorities around the world responded with very low interest rates and a wide range of non-standard, unconventional policy measures. However, the general public in Europe and in the US felt that monetary authorities did not respond appropriately to the economic downturn and only a small part of the public was confident in their policies to manage the crisis (FT/Harris poll, 2008 3 , 2009 ${ }^{4}$ ). As shown in Figure 1 and Figure 2, public opinion and attitudes towards central banks in Europe have been on a clear declining trend. In Figure 1 we observe that the net trust of European citizens in the ECB has strongly declined over the last years, with some countries suffering a stronger loss of trust in the ECB than others. The same declining trend can be observed when looking at the net satisfaction measure of British citizens with the BoE.

Overall, anemic post-crisis recovery, difficulties in the euro area governance and the recent debates on migration have strengthen dis-integrative forces in the EU. The net share of citizens expressing trust in several European institutions have dropped considerably, meaning that more people distrust the EU which would make gover-

\footnotetext{
${ }^{3}$ See "http://www.harrisinteractive.com/news/FTHarrisPoll/HI_FinancialTimes_HarrisPoll_October2008.pdf"

${ }^{4}$ See "http://www.harrisinteractive.com/news/datatables/HI_FT_HarrisPoll_Jüly2009.pdf"
} 
nance more difficult, lower shock resilience and limit internal market development. Although there is considerable variation in the evolution of net trust across countries, the ECB is one of the EU institutions to suffer as well from the loss of trust. As Figure 1 shows, the ECB benefited from relatively high levels of public support since its establishment until approximately 2009, enjoying positive levels of net trust in all countries under our study. During these years, the net trust has been relatively stable fluctuating only slightly in the years preceding the European sovereign debt crisis. However, starting with 2010-2011 a clear declining trend in public opinion towards the ECB is observed, with levels of net trust even turning negative for all the euro area countries in our study, meaning that the share of citizens distrusting the ECB was higher than the share trusting it.

Figure 1: Public opinion on ECB

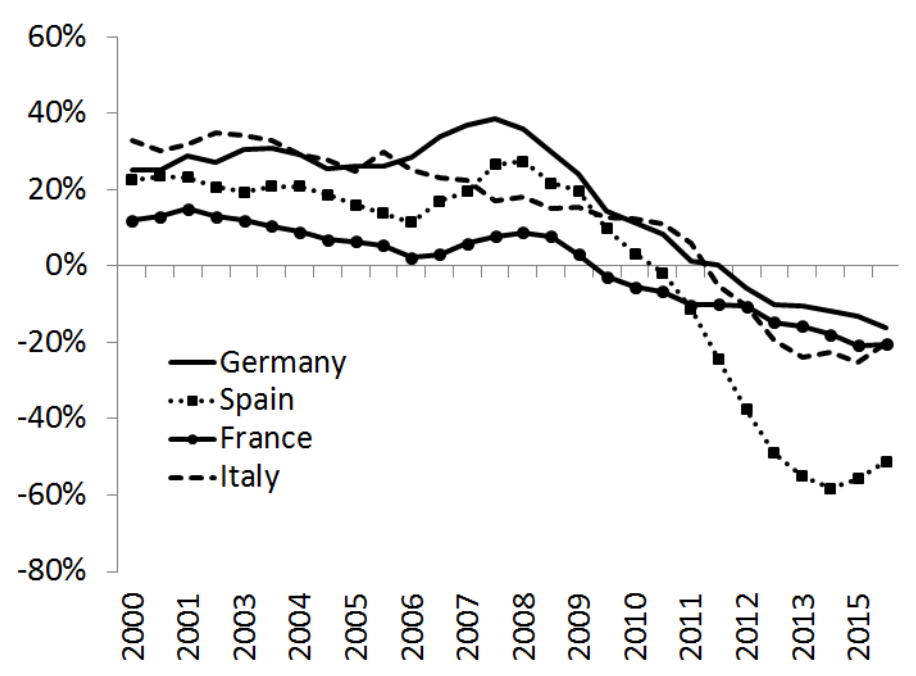

Notes: Four surveys moving average of the net trust in the ECB (defined as the difference between the share of respondents who state they tend to trust and the share of respondents who state they tend to not trust the ECB). Sources: Standard Eurobarometer Survey.

When considering individual countries, French citizens have expressed a lower level of trust in the ECB since the beginning compared with other countries and they have been the first to dip into negative territory in terms of trust. German and Italian citizens have been among the ones showing the highest levels of net trust in the ECB in the 2000s but they have also followed suit and the levels of net trust turned negative in 2011. Spain has suffered by far the largest drop in the net trust in the ECB which started to pick up only in 2014. Interestingly, around 2007-2008 there has been a slight pickup in the net trust in the ECB. This pickup in trust may be related to a "rally 'round the flag" effect which is a short-run boost of citizens' approval for their governments and institutions in times of terrorist attacks, natural catastrophes, wars or when economic crises begin (Waltz (1967), Mueller (1970)). 
When confronted with a common enemy, citizens will circle the wagons, providing additional support to the government, in order to fend off the threat (Chatagnier (2012)). The rise in the net trust in the ECB seems to coincide with the start of the financial crisis in the U.S. At that point of time, Europe appeared in a better situation than the U.S, as the spillovers from the US financial crisis to Europe had not materialized yet. The general public might have perceived this as a merit of the strong EU institutional framework and consequently expressed their support.

For the BoE (Figure 2, panel a) we observe as well a negative trend of the net satisfaction of British citizens. However, this measure is not falling into negative territory during or after the financial crisis as it was the case for the ECB. The BoE has resorted to unconventional monetary policy to stabilize the economy and inflation, in line with how the ECB proceeded. However, the British citizens seem to have been more approving and satisfied with the way the BoE has been doing its job than other European citizens. Net confidence in the BoE started to pick up again in late 2012 .

Figure 2: Public opinion on BoE and BoJ

(a) Net satisfaction with BoE

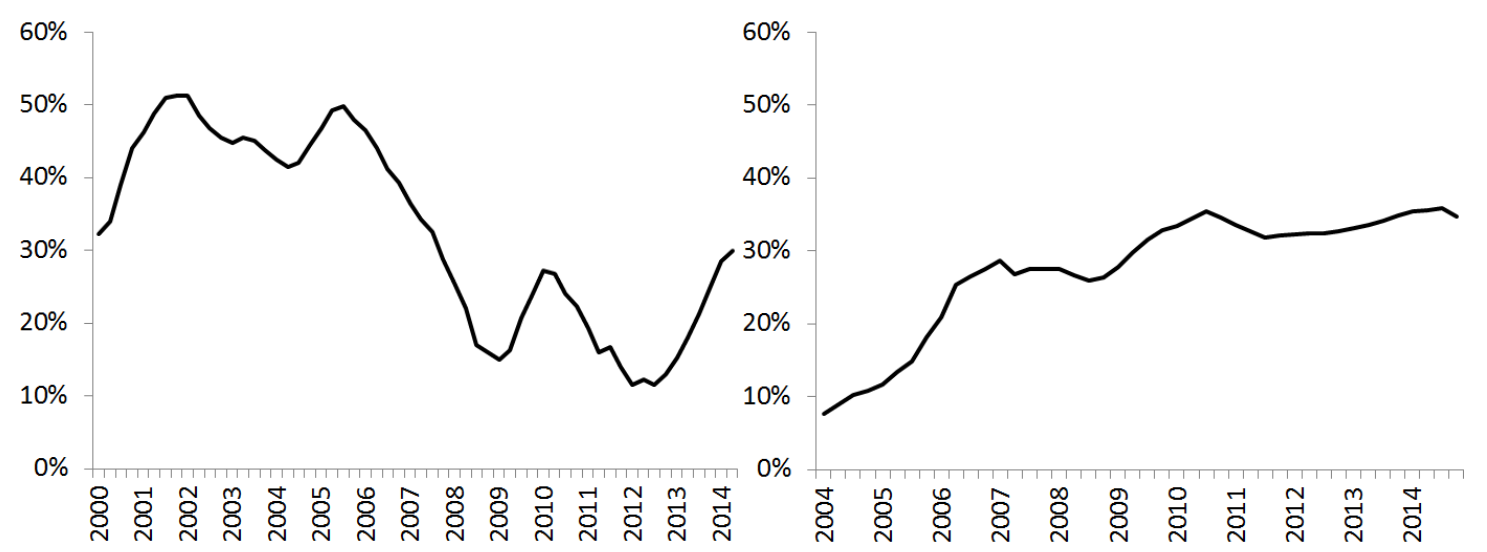

Notes: Four surveys moving average of net satisfaction with the BoE and of net confidence on BoJ. Sources: Bank of England, Inflation Attitudes Survey and Bank of Japan, Opinion Survey on the General Public's Views and Behavior.

The evolution of confidence of Japanese citizens in the BoJ (Figure 2, panel b) is very different from what we have observed for the ECB and the BoE. The measure of net confidence starts from very low levels in 2004 and since then it has been continuously trending upward. In Japan, in the late 1980s, large bubbles developed in the property and stock markets. Their burst was followed by a sluggish growth in the 1990s, also referred to as the "lost decade". Lingering effects of this were still felt in the 2000s, with the modest economic recovery in the mid-2000s being ended by the deep recession in 2008-2009, as elsewhere in the world. Moreover, 
Japan has long struggled with deflation which has become entrenched since the late 1990s and has had harmful effects on the economy. The BoJ has been pursuing more aggressive quantitative easing policies in order to end the deflationary spiral. Despite the persistent deflation, Japanese citizens have expressed increasing levels of confidence on the BoJ, thus being supportive of the BoJ efforts. The evolution of confidence had only a pause during the recent financial crisis but since 2009 it continues its upward trend, albeit with a slowdown.

Overall, we observe a clear declining trend of measures of public opinion on central banks (with the exception of BoJ) following the financial crisis. This is bad news for policy makers since it appears that they were losing citizens' trust and support in a situation in which it is particularly needed. The decline in trust is also acknowledged by the ECB. In an interview with the Financial Times in December 2011, the ECB president, Mario Draghi, stressed out that "the important thing is to restore the trust of the people - citizens as well as investors - in our continent. We won't achieve that by destroying the credibility of the ECB'. Furthermore, monetary authorities acknowledge that they depend on citizens' trust to secure their independence and credibility, which are key to the well-functioning of monetary policy transmission mechanism (see Gonzalez-Paramo, 2007 ${ }^{5}$, Asmussen, $2012^{6}$ ). The importance of reputation and credibility of central banks has also been recognized in theoretical research since the seminal work of Kydland and Prescott (1977) and Barro and Gordon (1983). Furthermore, trust is particularly essential at times of crisis, when economic uncertainty increases markedly and policy makers might need flexibility to change tactics or take unpleasant actions (Blinder (2000)). Although measures of public confidence in central banks may have been affected by several factors, in the following we will investigate whether overall uncertainty around economic policies has played an important role in shaping their evolution.

\section{Estimation methodology}

In this section we employ vector autoregressive models (VAR) to study the effects of policy-related uncertainty shocks on selected measures of public opinion towards central banks. More specifically, below we present the VAR model, the identification strategy and the results.

\footnotetext{
${ }^{5}$ Speech by Jose Manuel Gonzalez-Paramo, Member of the Executive Board of the ECB, Conference on "Inflation Targeting, Central Bank Independence and Transparency" Cambridge, 15 June 2007.

${ }^{6}$ Speech by Joerg Asmussen, Member of the Executive Board of the ECB, European Communication Summit 2012, Brussels, 6 July 2012, "Building trust in a world of unknown unknowns: central bank communication between markets and politics in the crisis".
} 


\subsection{VAR specification, data alignment and identification}

The VAR model employed for our analysis has the following standard representation:

$$
y_{t}=A_{0}+A_{1} y_{t-1}+\ldots+A_{p} y_{t-p}+B_{0} z_{t}+u_{t}
$$

for $t=1, \ldots, T$, where $y_{t}$ is a $n \times 1$ vector of endogenous variables, $z_{t}$ is a $m \times 1$ vector of exogenous variables, $\mathrm{p}$ is the number of lags and $u_{t}$ represents the reduced-form errors,

$$
u_{t} \sim \operatorname{iid} N(0, \Sigma)
$$

The vector of endogenous variables is $y_{t}=\left(e p u_{t}\right.$, macro $\left._{t}, p b o_{t}\right)$, with $e p u_{t}$ being the economic policy uncertainty variable, macro $_{t}$ being one of the macroeconomic variables (the industrial production, the unemployment rate or the CPI inflation rate) and $p b o_{t}$, a measure for the public opinion on the central bank. ${ }^{7}$ We employ Bayesian techniques for estimation following Uhlig (2005). The VAR coefficients are drawn from a normal-inverse-Wishart distribution with a flat prior. ${ }^{8}$ The optimal lag is selected based on the BIC information criteria and reported below each figure of results. Constrained by the availability of both the policy uncertainty measure on one side, and the measures of public opinion on the other, we will estimate the VARs for Germany, France, Italy, Spain, UK and Japan, only. ${ }^{9}$

As a measure of policy uncertainty $\left(e p u_{t}\right)$ we use the index of economic policy uncertainty (hereafter EPU) proposed by Bloom et al. (2016). The EPU index is constructed for several developed countries and is based on two components ${ }^{10}$ : the newspaper coverage of policy-related economic uncertainty and the disagreement of professional forecasters on expected inflation and government expenditures. This measure captures uncertainty about what policy actions the decision makers will undertake and uncertainty about the economic effects of current and future actions and/or inactions. This can be uncertainty about fiscal, monetary or other regulatory policies. In our estimations we use only the news-based component of the EPU. This component is based on automatic searches of specific terms related to the economic

\footnotetext{
${ }^{7}$ The individual VARs include a constant and oil prices as an exogenous variable. The inclusion of oil as an exogenous variable is to condition for price dynamics that are out of central bank's control.

${ }^{8} \mathrm{~A}$ flat prior allows us to use the benefits of the Bayesian techniques while having our results more data-driven, making them easily comparable with results in the related literature that do not use such methods for estimation.

${ }^{9}$ It would have been interesting to study the case of the U.S since data on policy uncertainty exist in subcategories. However, we are not aware of a measure of public opinion on the Federal Reserve.

${ }^{10}$ For the U.S it has an additional component, the number of federal tax code provisions set to expire in future years. For more information, visit www.policyuncertainty.com.
} 
uncertainty and policy in the largest newspapers for each country. The European indexes draw on two newspapers per country: Le Monde and Le Figaro for France, Handelsblatt and Frankfurter Allgemeine Zeitung for Germany, Corriere Della Sera and La Repubblica for Italy, El Mundo and El Pais for Spain. For the UK, the EPU index draws on The Times of London and Financial Times. For Japan it draws on the two largest-circulation daily newspapers, Asahi and Yomiuri.

Using a measure of policy uncertainty as discussed in the media is desirable especially when working with the opinion of the general public. The role of media in disseminating information and shaping public opinion is acknowledged in several studies. ${ }^{11}$ With respect to monetary policy, Berger et al. (2011) stress that media coverage of central bank's actions is important for the central bank's communication with the wider public, and thus an important factor for its credibility and policy effectiveness. They find that the press critically discusses the ECB's policy decisions in the context of prior market expectations and of the inflation environment and that the ECB's media coverage is generally highly responsive to ECB communication. Moreover, media tends to report more on negative news. Given that uncertainty is usually considered negative, it is more likely to be reported by the media.

The news-based EPU measure of Bloom et al. (2016) used in this paper refers to uncertainty about different economic policies (like fiscal, monetary or regulatory policies), thus it is an overall economic policy uncertainty measure. Bloom et al. (2016) do not provide yet specific EPU measures for monetary policy for the euro area countries and the UK. However, their measures for the U.S show that the overall EPU measure is not very different across main policy categories like fiscal policy or monetary policy. For instance, the correlation between the EPU and a measure of monetary policy uncertainty in the U.S during 1999-2014 is about 0.8, and for fiscal policy 0.9 , indicating a close evolution of these sub-measures with the overall EPU measure. Moreover, in general, the broad public is often not as specialized to differentiate institutions responsible for a particular economic policy. For instance, during the Euro Crisis, the ECB (as part of Troika together with the IMF and the European Commission) was often criticized in countries under the financial assistance programme. ${ }^{12}$ Ultimately, it remains an empirical question whether the trust of citizens in the ECB is hurt by these developments, thereby holding the ECB accountable even for issues that do not fall under its mandate.

\footnotetext{
${ }^{11}$ Doms and Morin (2004) explore the linkages between media coverage of economic events, consumers' perceptions, and economic outcomes and Berger et al. (2011) explore the relation between economic policymaking and media coverage.

${ }^{12}$ Troika established the conditions on which financial assistance, or promises of assistance, would be given to indebted European countries.
} 
Figure A.1 in appendix A shows the evolution of country specific measures of economic policy uncertainty (EPU) as measured in Bloom et al. (2016). In Europe, economic policy uncertainty was relatively elevated at the beginning of 2000s but it went down in the years preceding the recent global financial crisis. France has experienced high levels of the EPU in 2001, coinciding with the $9 / 11$ event. Spain has also experienced an episode of high uncertainty in 2002-2003, around the vast demonstrations against military interventions in Iraq. During the financial crisis one can observe that the EPU has increased considerably across all countries and it has become more volatile than before. The strongest increase in the EPU in the aftermath of the crisis can be observed in the UK, France and Germany. Compared to other countries, the uncertainty around economic policies as presented by the media has been lower and more stable in Japan.

Our variables of interest are available at different frequencies: monthly - policy uncertainty, industrial production, inflation, and unemployment; quarterly - net satisfaction measure for the BoE; biannual - the net trust in the ECB and the net confidence in the BoJ. The VARs are estimated on a quarterly frequency in the case of the BoE and on a biannual frequency for the ECB (mid 1999 to end 2014) and the BoJ (mid 2003 to end 2014). The data for each country is aggregated and aligned to fit our identification strategy which is discussed in details below. The industrial production and the EPU index enter the VARs in log levels, and the unemployment rate and inflation rate in percent.

Identification. To identify the effects of policy uncertainty we use a recursive identification strategy with variables included in the VAR ordered as follows: epu $u_{t}$, macro $_{t}$, pbo $_{t}$. Under this ordering policy uncertainty does not contemporaneously respond to other shocks while an innovation to it can have an immediate effect on the variables ordered after. We motivate this identification strategy by the timing of the surveys. That is, we carefully take into account the timing of the field work of the surveys when designing the identification strategy for our analysis. We align the VAR data in such a manner, that economic policy uncertainty is observed (measured) before the start of the fieldwork of each survey. This is regardless of the month in which the survey is published or how long the field work is. In this way we would like to avoid the contemporaneous feedback from public opinion on economic policy uncertainty measures. We aggregate economic policy uncertainty measure and the macroeconomic indicators taking averages over the three months (for quarterly surveys) or six months (for biannual surveys) prior to the publishing date of the surveys (more details about the surveys, when they are published and when the field work usually happens are presented in the previous section). In practice the 
implementation of this alignment strategy is more complicated as the publishing dates and fieldwork periods differ across surveys. Therefore the aggregation of the policy uncertainty measure and of the macroeconomic indicators had to be done for each survey individually.

For instance, if a Eurobarometer survey (at a biannual frequency) is published at the end of November and the fieldwork is spanning from September until November, then the averages of the policy uncertainty measure and of the macroeconomic indicators are taken over the six months prior to September (from March until August). The same procedure is applied when aligning the data in the case of Bank of Japan. The only difference is the length of the field work which is usually one month before the publishing of the survey's results. In the case of the Inflation Attitudes Survey of BoE, the fieldwork is usually done in the month prior to the publishing of the results. Therefore, the fieldwork of a survey published at the end of June is spanning through the month of June. The policy uncertainty measure and the macroeconomic variables are aggregated in this case taking averages across the three months prior to the beginning of the fieldwork (from March to May, for instance). ${ }^{13}$

In our benchmark estimation, the ordering of the EPU with respect to the macroeconomic variables is not as strongly motivated as in the case of survey measures. However, in practice, macroeconomic statistics are observed always with delay to the month when the EPU is observed (due to lags in publishing of macro statistics) therefore we should not expect a contemporaneous feedback from the macroeconomic indicators on the EPU measure. However, since we work with averages across six months (or three in the case of BoE), this feature is less likely to be preserved. We will investigate a reverse ordering of the variables in a sensitivity analysis. $^{14}$

\section{Empirical results}

In this section we discuss the empirical results from the estimation of individual Bayesian VARs (BVARs) for the selected euro area countries, the UK and the Japan. As it is common in this literature, a policy uncertainty shock corresponds to an increase of two standard deviations in the policy uncertainty measure (here the EPU).

\footnotetext{
${ }^{13}$ The measures of public opinion are described in Section 2. No transformation (aggregation or averaging) has been performed on them.

${ }^{14}$ The exogenous assumption is broadly in line with how uncertainty is treated in most of theoretical models. For example, in Fernandez-Villaverde et al. (2015), the process for policy uncertainty, represented by the stochastic volatility of the policy instrument, is exogenous and an innovation to it has an immediate impact on economic activity.
} 
Figure 3: Responses to a policy uncertainty shock (Industrial Production as macro variable)

(a) Germany
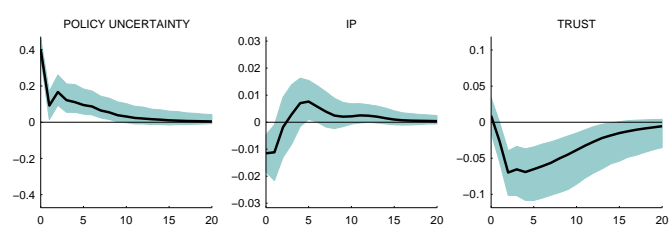

(c) Italy
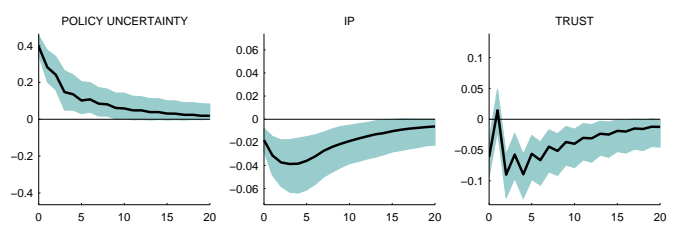

(e) United Kingdom
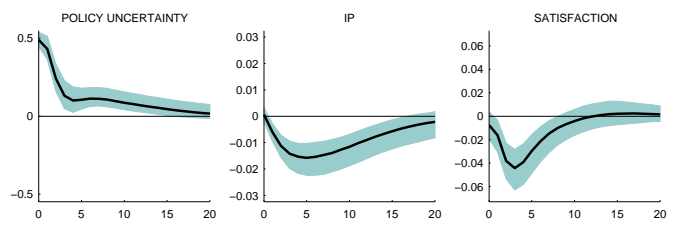

(b) France
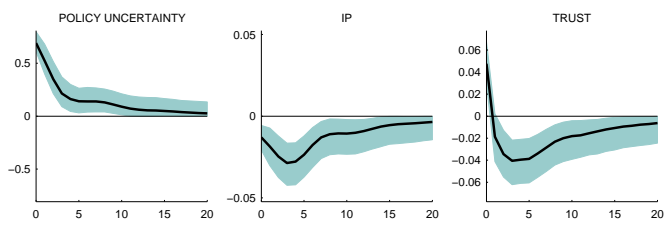

(d) Spain
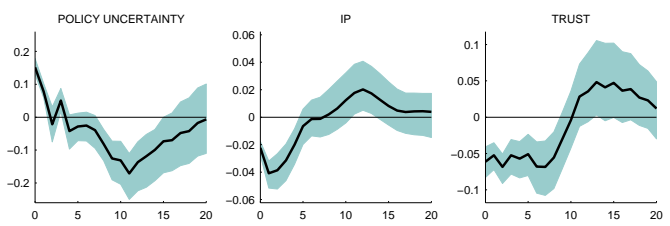

(f) Japan
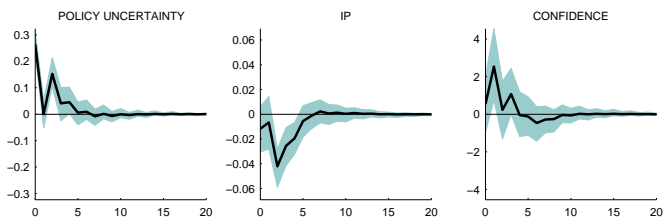

Notes: The variables included in the VAR are ordered in the following way: eput, $i p_{t}, p b o t$, where epu denotes the policy uncertainty measure, ip denotes Industrial Production, and $p b o$ is the corresponding variable for public opinion on the central bank. The solid line in black denotes median impulse response from an estimated Bayesian VAR(3). The shaded areas represent the corresponding 68 percent error band. Horizontal axis is the horizon in half years for BoJ and ECB and in quarters for the BoE. 
The dynamic responses of our variables of interest (including industrial production as a measure of economic activity) to innovations to EPU are shown in Figure 3. Our results suggest that policy uncertainty shocks are associated with economic contractions, which appear to happen immediately for Germany, France, Italy and Spain. In terms of magnitude, Spain, Italy and Japan appear to suffer the biggest fall in industrial production, of about 4 percent, in response to a two standard deviation shock in the EPU. The estimated impulse response functions show heterogeneity even in terms of the persistence of output contraction. The recovery of industrial production to initial levels is slow and very persistent for the UK, Italy and France while for Germany and Spain we observe a faster rebound and an overshoot. ${ }^{15}$

Furthermore, an innovation to policy uncertainty is also associated with a relatively sharp deterioration in public opinion measures towards the ECB (in Germany, France, Italy and Spain) and the BoE (in the UK). The strongest drop in the net trust in response to a policy uncertainty shock is observed for Italy, followed by Spain and France. Interestingly, for the euro area countries the variable of trust takes longer to revert back to the initial level compared to the industrial output, in response to the EPU shock. Taking a couple of periods more than the economy to revert back to the equilibrium reflects the fact that trust or confidence is easy to lose but hard to rebuild. Differently, the UK enjoys a faster rebound in the BoE's net satisfaction measure after an EPU shock materializes. In contrast, while Japan also exhibits a large contraction in industrial production (about 4 percent), there is an increase in the net satisfaction with the BoJ. However, even though the median response is positive for the BoJ, the credible bands include zero, thus the response is not significant.

In order to have a better understanding of the mechanisms through which policy uncertainty affects measures of public confidence on central banks, we look separately at structural VARs where economic conditions are accounted for either by the unemployment rate or by the CPI inflation rate. ${ }^{16}$ When we estimate the VAR models including the unemployment rate as the macroeconomic factor, the results of the benchmark VARs (in which industrial production is included) continue to hold. These results are presented in Figure 4. Shocks to policy uncertainty raise the unemployment rate considerably for all countries and reduce public confidence in central banks. The rise in the unemployment rate is immediate and particularly

\footnotetext{
${ }^{15}$ The latter effect has been discussed in the literature on uncertainty, see (Bloom, 2009).

${ }^{16}$ Including both variables simultaneously in the VAR would increase the numbers of parameters that need to be estimated. Given the relative small number of observations available for our analysis we chose to estimate the VARs with three variables only. In the robustness analysis we estimate a four variable VAR.
} 
strong for Spain (above 2 percentage points) and for Italy (around 1 percentage point). Only in the case of Germany the effect of a policy uncertainty shock on the unemployment rate is imprecisely estimated (the confidence zone includes the zero). ${ }^{17}$

Figure 4: Responses to a policy uncertainty shock (unemployment as macro variable)

(a) Germany
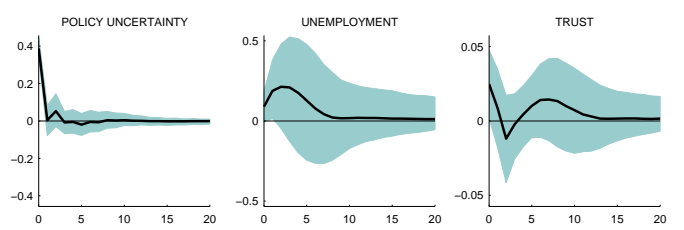

(c) Italy
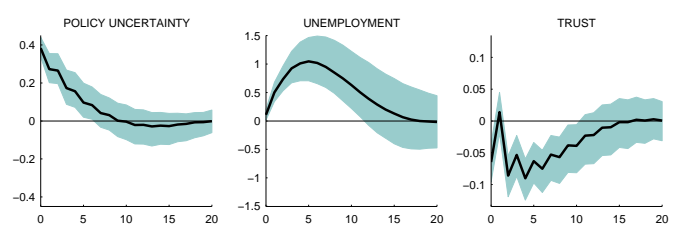

(b) France
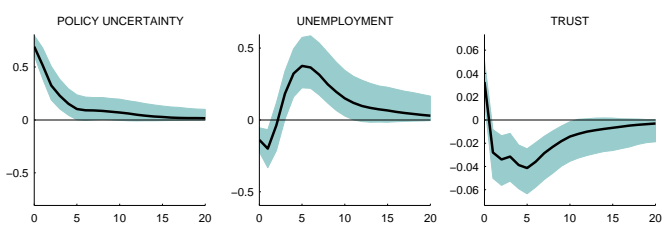

(d) Spain
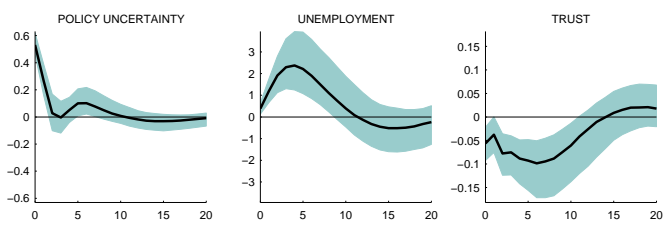

(e) United Kingdom

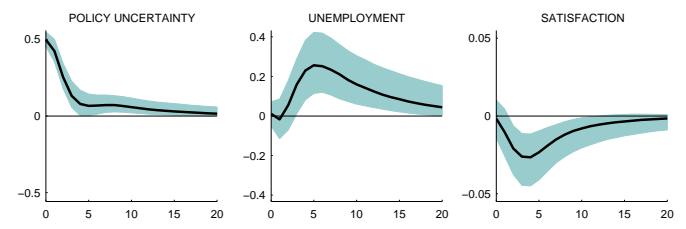

Notes: The variables included in the VAR are ordered in the following way: $e p u_{t}, u_{t}, p b o_{t}$, where $e p u$ denotes the policy uncertainty measure, $u$ denotes the unemployment rate and $p b o$ is the corresponding variable for public opinion on central banks. The solid line in black denotes median impulse response from an estimated Bayesian VAR(3). The shaded areas represent the corresponding 68 percent error band. Horizontal axis is the horizon in half years for the ECB and in quarters for the BoE.

With unemployment rate as a macroeconomic factor in the VAR model we observe that shocks to policy uncertainty have a relatively large effect on the net trust in ECB for the case of Spain, while this effect remains in the same ballpark levels as in the previous estimation for France and Italy. On the other hand, responses of net trust appear to be weaker in the case of the UK and Germany. This result suggests that policy uncertainty is affecting public opinion towards central banks beyond the negative effect it has on unemployment, a variable that is usually found to be playing an important role in the trust-building process for public institutions.

The results of the VAR estimations in which we include inflation show the same negative effect of policy uncertainty on public opinion variables (Figure 5). As in the case when the unemployment rate is included in the VAR specification, we observe

\footnotetext{
${ }^{17}$ The VAR estimation for Japan for this specification is not stable therefore we omit showing this result.
} 
that shocks to policy uncertainty have a larger negative effect on public opinion for Spain and Italy. Interestingly, in the case of the UK, the responses of both consumer prices and the measure of public confidence to an innovation to policy uncertainty are not precisely estimated. This result suggests that, once we account for the dynamics of the CPI inflation, the drop in net confidence in the BoE in response to the EPU shock is less significant. ${ }^{18}$

Figure 5: Responses to a policy uncertainty shock (inflation as macro variable)

(a) Germany
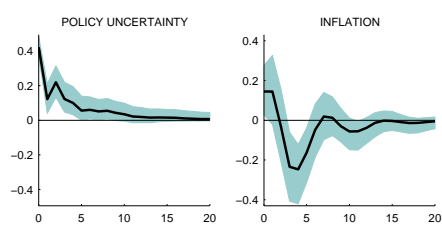

(c) Italy
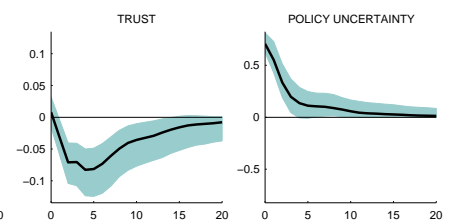

(b) France

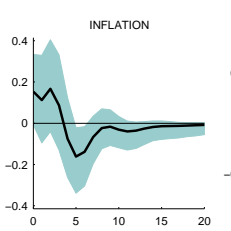

(d) Spain

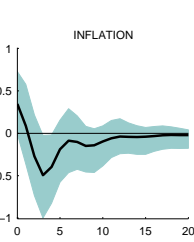

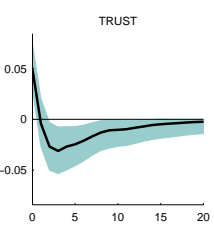

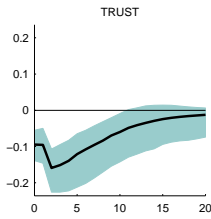

(e) United Kingdom

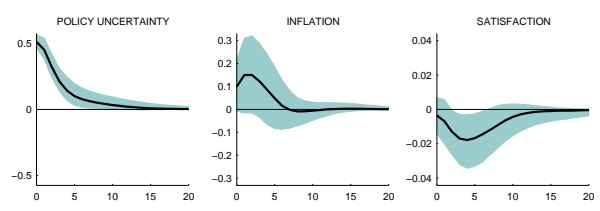

Notes: The variables included in the VAR are ordered in the following way: $e p u_{t}, c p i_{t}, p b o_{t}$, where $e p u$ denotes the policy uncertainty measure, cpi denotes the CPI inflation rate and pbo is the corresponding variable for public opinion on central banks. The solid line in black denotes median impulse response from an estimated Bayesian $\operatorname{VAR}(3)$. The shaded areas represent the corresponding 68 percent error band. Horizontal axis is the horizon in half years for the ECB and in quarters for the BoE.

Innovations to policy uncertainty may affect public confidence on central banks both directly and indirectly, through the negative effects that uncertainty has on the overall economy. Indirectly, one would expect the transmission to be mainly through the effect of the EPU on inflation. However, we observe that even when controlling for the dynamics in consumer prices, the EPU shock has additional effect in our selected measures of confidence. That means that the inflation channel does not fully account for the transmission of the EPU shocks. We observe that only in the case of the UK the effect of the EPU weakens when we account for inflation dynamics. By the same token, the argument holds with respect to including unemployment in

\footnotetext{
${ }^{18}$ The VAR estimation for Japan for this specification is not stable therefore we omit showing this result.
} 
the VAR. Overall, the EPU shocks explain additional variation of the confidence measure when unemployment is accounted for. Germany is an exception, where under this specification, policy uncertainty does not seem to play a role in shaping the dynamics of neither the unemployment rate nor the net trust in the ECB.

Through our analysis and under our identification strategy we allow the relationship between economic conditions and public attitudes to be dynamic. An economy that is well performing might have positive effects on public attitudes towards institutions which would, in turn, feed back into the economy as agents are more optimistic about the economic outlook and they are more prone to consume, invest, hire new personnel, or enter into business relationships. This feedback loop also holds when bad economic conditions materialize, as they could hinder general public confidence in institutions. The negative attitudes would then affect the economic and financial behavior of the agents, feeding back into the economy and dragging economic activity down even further. Our results reflect this feedback loop well as we observe that in response to an EPU shock, economic activity takes years to return to the initial levels when we control for public attitudes towards central banks. This is because negative attitudes also weight on the recovery, making it slower.

\subsection{Robustness Analysis}

In the following we examine whether our main results are sensitive to issues related to the identification of the economic policy uncertainty shocks. In our benchmark identification, we use the timing of the surveys and the alignment of the data in the VAR to justify the assumption that policy uncertainty responds immediately only to its own innovations and with a period delay to other shocks. However, with respect to the relationship between policy uncertainty and macroeconomic variables this assumption might be too constraining. Therefore, as a sensitivity analysis, we reverse the ordering of the EPU with the macroeconomic variable, allowing the EPU measures to be contemporaneously responsive to macroeconomic shocks.

The empirical results of the sensitivity analysis are shown in Figure 6 and Figure 7 , with the industrial production and the unemployment rate as macro variables. In Figure 6 we observe that our benchmark results hold even after we reorder the variables in the VAR. Shocks to economic policy uncertainty still have a contractionary effect on the economy across all countries and reduce public confidence in central banks. The negative effect of the EPU shock on the economy mutes for the case of Germany and it is less precisely estimated for Spain, compared to the baseline results.

When reordering the VAR with the unemployment rate we observe qualitatively 
Figure 6: Reordering: Industrial Production (IP) as macro variable

(a) Germany
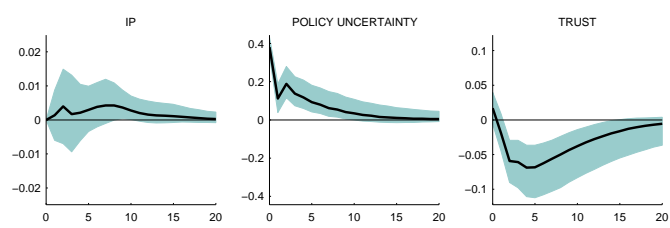

(c) Italy
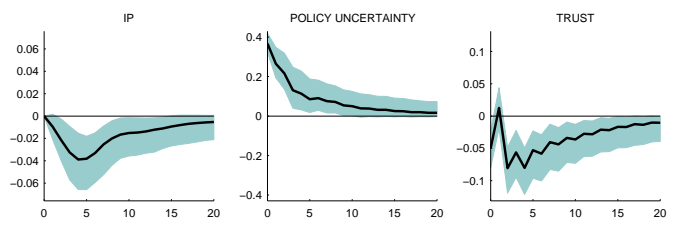

(e) United Kingdom
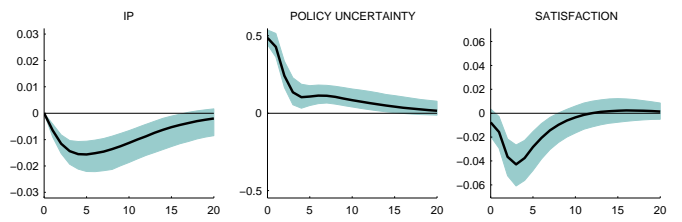

(b) France
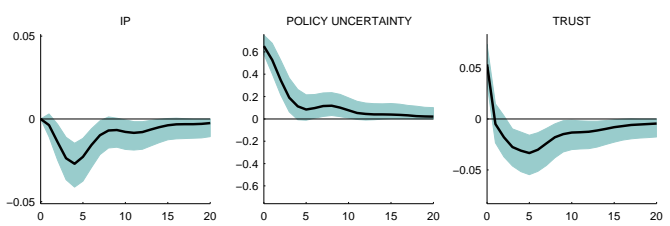

(d) Spain
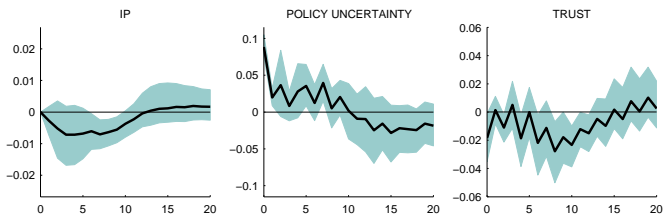

(f) Japan
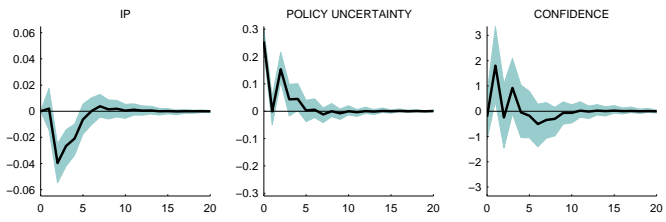

Notes: The variables included in the VAR are ordered in the following way: $i p_{t}, e p u_{t}, p b o t$, where $e p u$ denotes the policy uncertainty measure, ip denotes the industrial production and $p b o$ is the corresponding variable for public opinion on central banks. The solid line in black denotes median impulse response from an estimated Bayesian $\operatorname{VAR}(3)$. The shaded areas represent the corresponding 68 percent error band. Horizontal axis is the horizon in half years for BoJ and ECB and in quarters for BoE. 
Figure 7: Reordering: Unemployment as macro variable

(a) Germany
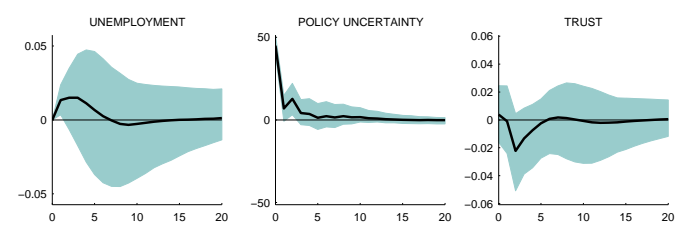

(c) Italy
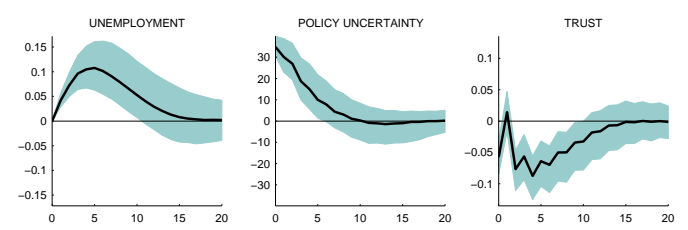

(e) United Kingdom

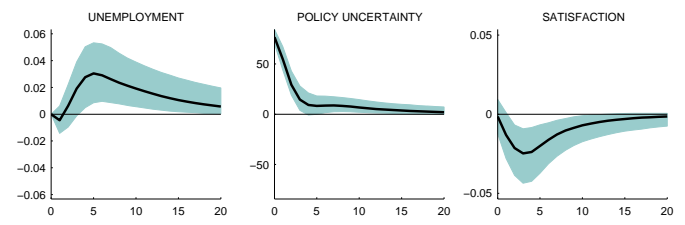

(b) France
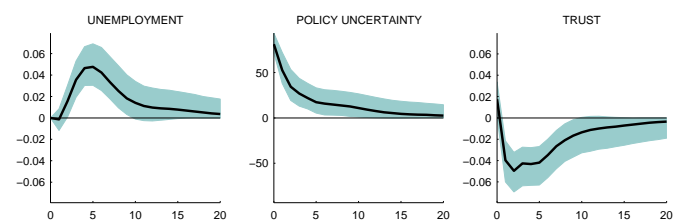

(d) Spain
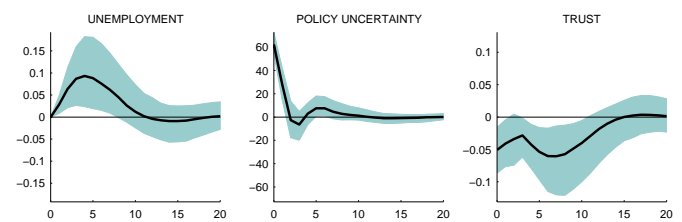

(f) Japan
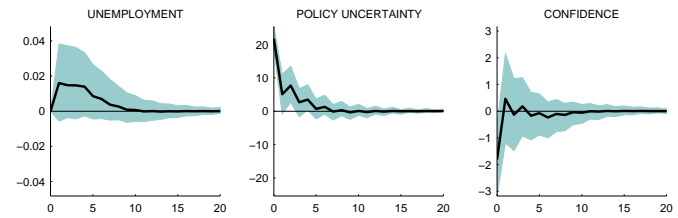

Notes: Notes: The variables included in the VAR are ordered in the following way: $u_{t}, e p u_{t}, p b o t$, where epu denotes the policy uncertainty measure, $u$ denotes the unemployment rate and $p b o$ is the corresponding variable for public opinion on central banks. The solid line in black denotes median impulse response from an estimated Bayesian SVAR(3). The shaded areas represent the corresponding 68 percent error band. Horizontal axis is the horizon in half years for BoJ and ECB and in quarters for BoE. 
similar results. However, from a quantitative point of view, the effects seem to be weaker. Interestingly for Japan, the initial effect on the confidence on the BoJ is strongly negative given a shock to policy uncertainty (the median response) but very fast this response is not significantly different from zero. As mentioned before, the imprecision of the estimates for Japan could be due to the short data sample available for our analysis.

In another robustness exercise we extend the number of variables in the VAR, including both the unemployment rate and the inflation rate as macro variables. These results are very similar to our benchmark VARs with these macro variables entering separately (see Figure B.1 and B.2 in appendix B). The response of inflation to an EPU shock continues to be non-uniform across countries while the unemployment rate generally increases and public opinion measures deteriorate in response. The result on inflation relates with the analysis in Istrefi and Piloiu (2014) in which EPU shocks have an opposite effect on short-term and long-term inflation expectations of professional forecasters in the U.S and in the euro area. In this analysis, looking at different surveys of professional forecasters (the Consensus Economics and the SPF forecasts) Istrefi and Piloiu (2014) show that short-term (one year ahead) inflation expectations fall, reflecting the economic slack while long-term ( 5 years ahead) inflation expectations rise, probably reflecting low confidence or credibility in the central bank to maintain its inflation objective in the long run. This long-term expectations channel could be the mechanism through which policy uncertainty shocks lead to higher inflation on impact. ${ }^{19}$

Overall, we find that shocks to economic policy uncertainty induce economic contractions and relatively sharp deterioration in trust or satisfaction measures, which in general take longer than the economic growth to re-build. When comparing results across different central banks we should be careful to note that measures of public confidence for the ECB and the BoJ are relatively general as they are based on broader questions of trust and confidence. ${ }^{20}$ Differently, the measure of satisfaction with the BoE is specifically tailored to the main objective of the central bank, as British citizens are asked explicitly whether they are satisfied with the way BoE is doing its job to set interest rates in order to control inflation. That is, relative to the BoE's measure, the two other measures may differ depending on the definition of trust and confidence that each respondent perceives when answering

\footnotetext{
${ }^{19}$ In addition, Istrefi and Piloiu (2014) show that monetary policy-related uncertainty is not always the sole important factor behind the dynamics of inflation expectations. Fiscal policyrelated uncertainty seems to also play an important role.

${ }^{20}$ Another caveat relates with the short sample that is used for this VAR analysis which introduces imprecision on estimates. One way to deal with this small sample issue could be to use local-projection methods in the spirit of Jorda (2005). We leave this exercise for future research.
} 
the question. Nevertheless, all these measures broadly reflect a positive or a negative attitude towards the central bank. ${ }^{21}$ Holding positive attitudes is crucial to promote sustainable economic activity and is especially important for a central bank that needs to preserve its autonomy. In our analysis we show that economic policy uncertainty not only has negative effects on macroeconomic outcomes (in line with previous studies) but also plays a role in shaping the dynamics of public opinion on central banks in Europe (the BoE and the ECB).

\section{Concluding remarks}

Trust and confidence in institutions is important for the success of a wide range of policies as it affects the economic behavior of the agents in an economy, including expectations formation and the approval of the institutions, among others. Positive public attitudes support the confidence of investors and consumers and play an essential role for key economic activities, especially for financial activities.

In this paper we employed Bayesian VAR techniques to analyze the dynamic relationship between economic policy uncertainty and public attitudes towards the ECB, the Bank of England and the Bank of Japan. We show that in response to a shock to economic policy uncertainty, public confidence in monetary authorities deteriorates sharply and takes a long time to recover. These effects are observed for several measures of public confidence that are based on different surveys, across different countries and controlling for several macroeconomic indicators.

The deterioration of public confidence in response to policy uncertainty shocks should be worrying for policymakers, especially in an environment where economic policy uncertainty has become more volatile, as the lack of trust and confidence hinders the willingness of citizens and firms to respond to policies and contribute to a sustainable economic recovery. In the current economic environment of low interest rates, trust and credibility in the central bank is even more important for the success of unconventional policies that rely on commitment on future actions, like the forward guidance on rates and balance sheet policies.

\footnotetext{
${ }^{21}$ The OECD has adopted a definition of trust as an attitude that shapes behavior, and derives from past experience and expectations.
} 


\section{References}

Alexopoulos, M., Cohen, J., 2009. Uncertain times, uncertain measures, working Papers 352, University of Toronto.

Backus, D., Driffill, J., 1985. Inflation and Reputation. The American Economic Review 75 (3), 530-538.

Barro, R., Gordon, D., 1983. Rules, discretion, and reputation in a model of monetary policy. Journal of Monetary Economics 12(1), 101-121.

Berger, H., Ehrmann, M., Fratzscher, M., 2011. Monetary Policy in the Media. Journal of Money, Credit and Banking 43, 689-709.

Blinder, A. S., 2000. Central-bank credibility: Why do we care? How do we build it? The American Economic Review 90(5), 1421-1431.

Bloom, N., 2009. The impact of uncertainty shocks. Econometrica 77(3), 623-685.

Bloom, N., Baker, S. R., Davis, S. J., 07 2016. Measuring Economic Policy Uncertainty. The Quarterly Journal of Economics 131 (4), 1593-1636.

Bordo, M., Siklos, P., 2014. Central bank credibility, reputation and inflation targeting in historical perspective, NBER Working Papers 20693, National Bureau of Economic Research, Inc.

Bursian, D., Furth, S., 2015. Trust Me! I am a European Central Banker. Journal of Money, Credit and Banking 47 (8), 1503-1530.

Chatagnier, J. T., 2012. The effect of trust in government on rallies 'round the flag. Journal of Peace Research 49 (5), 631-645.

Doms, M., Morin, N., 2004. Consumer sentiment, the economy, and the news media, Working Papers in Applied Economic Theory, Federal Reserve Bank of San Francisco.

Ehrmann, M., Fratzscher, M., 2011. Politics and monetary policy. The Review of Economics and Statistics.

Ehrmann, M., Soudan, M., Stracca, L., 2013. Explaining EU citizens trust in the ECB in normal and crisis times. Scandinavian Journal of Economics 115(3), 781807.

Fernandez-Villaverde, J., Guerron-Quintana, P., Kuester, K., Rubio-Ramirez, J., 2015. Fiscal volatility shocks and economic activity. American Economic Review- 
Forthcoming.

Guiso, L., Sapienza, P., Zingales, L., 2006. Does culture affect economic outcomes? Journal of Economic Perspectives 20 (2), 23-49.

Howitt, P., 1982. Anti-inflation policy with a skeptical public : A comment on the Meyer-Webster paper. Carnegie-Rochester Conference Series on Public Policy 17 (0), 109-113.

Istrefi, K., Mouabbi, S., 2018. Subjective interest rate uncertainty and the macroeconomy: A cross-country analysis. Journal of International Money and Finance 88, 296-313.

Istrefi, K., Piloiu, A., 2014. Economic policy uncertainty and inflation expectations, Banque de France Working Paper, 511.

Jorda, O., 2005. Estimation and inference of impulse responses by local projections. American Economic Review 95 (1), 161-182.

Knack, S., Keefer, P., 1997. Does social capital have an economic payoff? a crosscountry analysis. Quarterly Journal of Economics 112 (4), 1251-88.

Kydland, F., Prescott, E., 1977. Rules rather than discretion: The inconsistency of optimal plans. Journal of Political Economy 85(3), 473-492.

Leduc, S., Liu, Z., 2016. Uncertainty shocks are aggregate demand shocks. Journal of Monetary Economics 82, 20-35.

Mueller, J. E., 1970. Presidential popularity from Truman to Johnson. American Political Science Review 64 (1), 18-34.

Mumtaz, H., Zanetti, F., 2013. The impact of the volatility of monetary policy shocks. Journal of Money, Credit and Banking 45(4), 535-558.

Roth, F., Gros, D., Nowak-Lehmann, F., 2012a. Has the financial crisis eroded citizens' trust in the European Central Bank? - Panel evidence for the euro area, 1999-2011, university of Goettingen, CEGE Discussion Paper, No. 124.

Roth, F., Jonung, L., Nowak-Lehmann, F., 2012b. Public support for the single European currency, the euro, 1990 to 2011. Does the financial crisis matter?, department of Economics, Lund University, Working Papers Series, WP1220.

Uhlig, H., 2005. What are the effects of monetary policy on output? results from an agnostic identification procedure. Journal of Monetary Economics 52.

Wälti, S., 2012. Trust no more? The impact of the crisis on citizens' trust in central 
banks. Journal of International Money and Finance 31(3), 593-605.

Waltz, K. N., 1967. In: Electoral punishment and foreign policy crises. James N Rosenau (ed.) Domestic Sources of Foreign Policy, New York: Free Press, 263294. 


\section{A Evolution of Economic Policy Uncertainty}

Figure A.1: Evolution of economic policy uncertainty across countries

(a) Germany

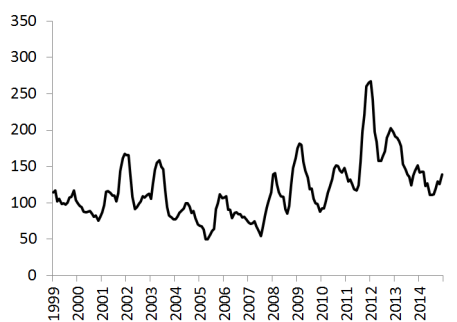

(c) Italy

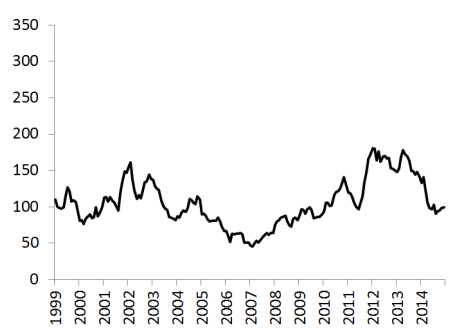

(e) United Kingdom

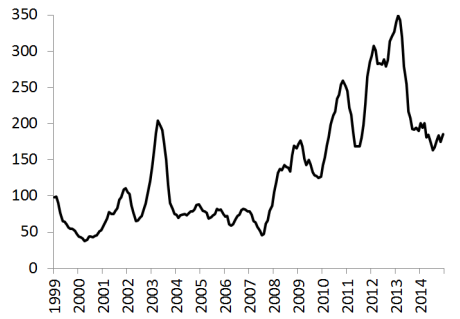

(b) France

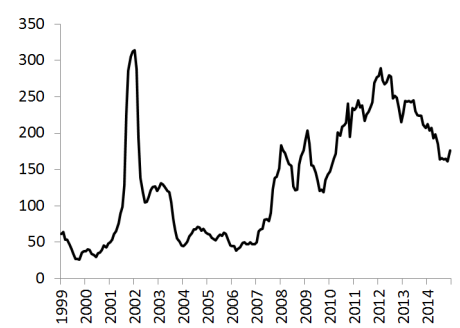

(d) Spain

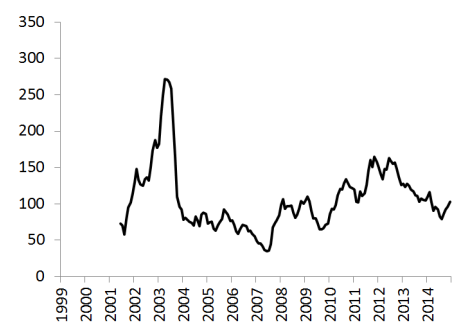

(f) Japan

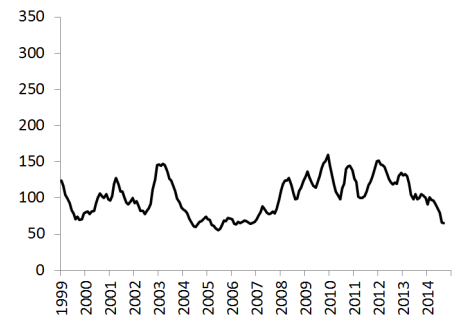

Notes: Six months moving average of the economic policy uncertainty index.

Source: http://www.policyuncertainty.com/, Bloom et al. (2016) 


\section{B Results alternative specifications}

Figure B.1: Impulse responses in a 4 variable VAR for EA countries

(a) Germany
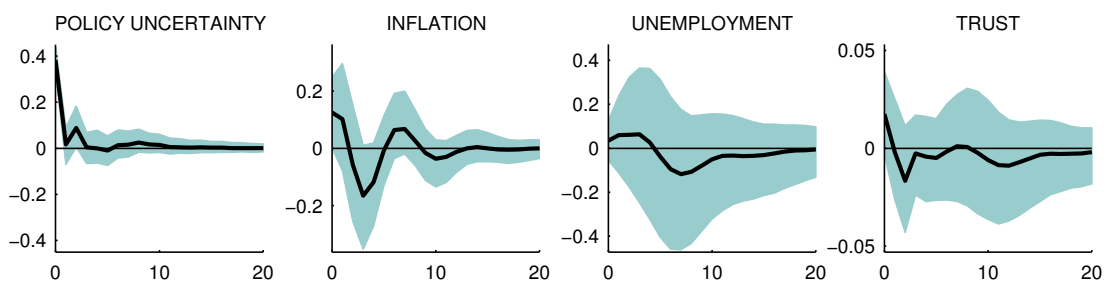

(b) France
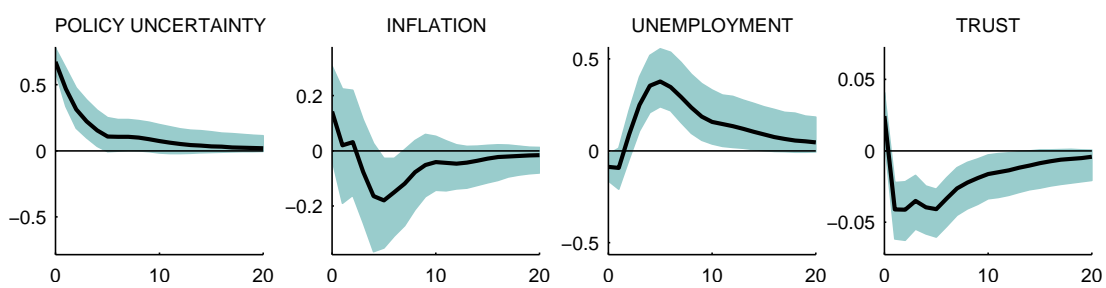

(c) Italy
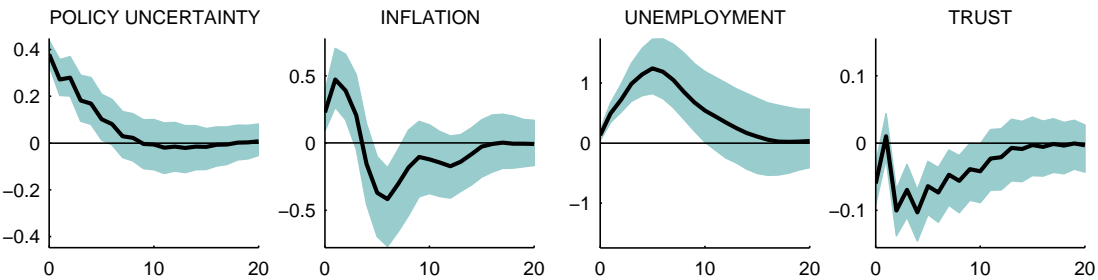

(d) Spain
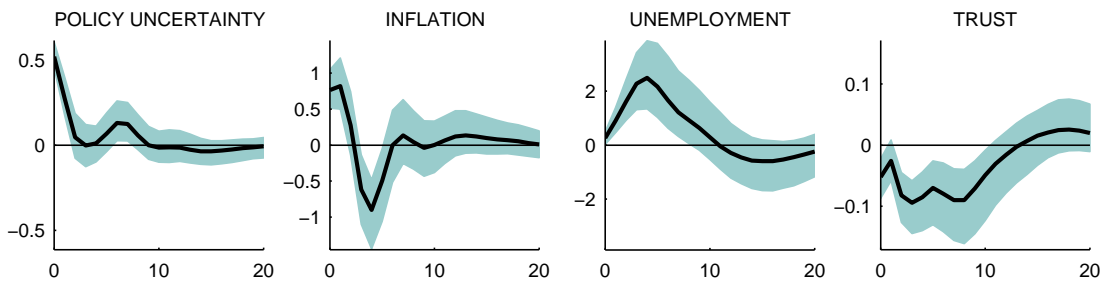

Notes: The variables included in the VAR are ordered in the following way: $e p u_{t}, c p i_{t}, u_{t}, p b o_{t}$, where epu denotes the policy uncertainty measure, $c p i$ denotes inflation, $u$ denotes the the unemployment rate, and $p b o$ is the corresponding variable for public opinion on the central bank. The solid line in black denotes median impulse response from an estimated Bayesian VAR(3). The shaded areas represent the corresponding 68 percent error band. Horizontal axis is the horizon in half years. 
Figure B.2: Impulse responses in a 4 variables VAR for UK and Japan

(a) UK
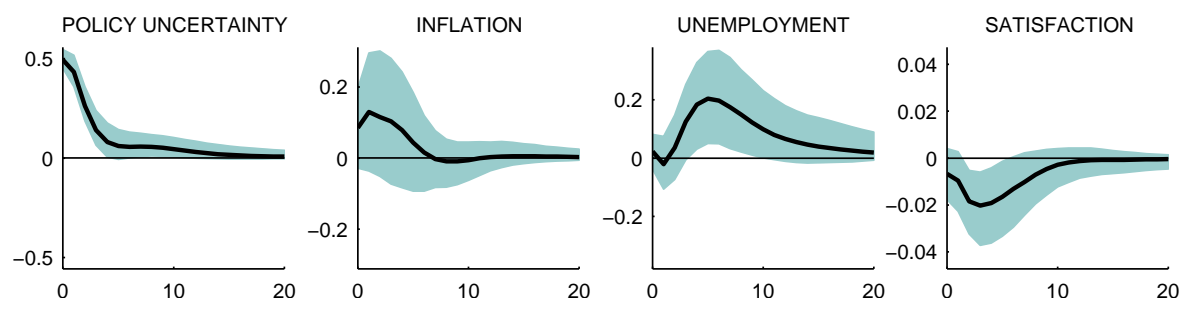

(b) Japan
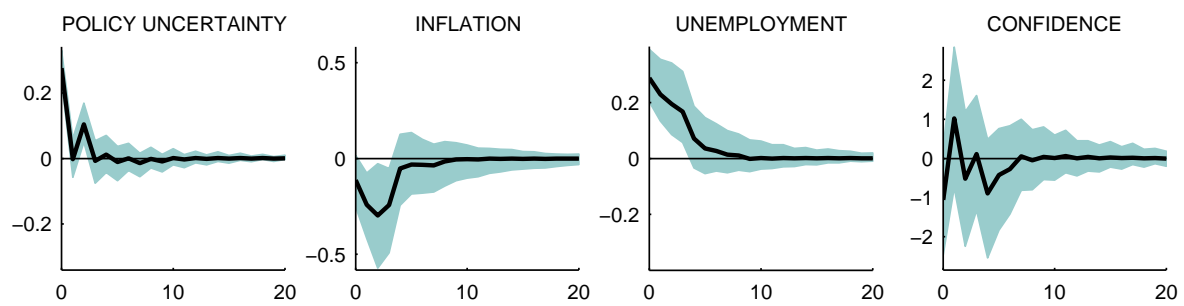

Notes: The variables included in the VAR are ordered in the following way: eput, $c p i_{t}, u_{t}, p b o_{t}$, where $e p u$ denotes the policy uncertainty measure, cpi denotes inflation, $u$ denotes the the unemployment rate, and $p b o$ is the corresponding variable for public opinion on the central bank. The solid line in black denotes median impulse response from an estimated Bayesian VAR(3). The shaded areas represent the corresponding 68 percent error band. Horizontal axis is the horizon in half years for the BoJ and in quarters for the BoE. 